\title{
The evaluation of safety efficiency of non-urban infrastructure improvements; a case-study
}

\author{
Victoria Gitelman • Roby Carmel • Fany Pesahov
}

Received: 18 December 2013 / Accepted: 13 July 2014 / Published online: 13 August 2014

(C) The Author(s) 2014. This article is published with open access at SpringerLink.com

\begin{abstract}
Objective This study examined the safety efficiency of infrastructure improvements applied on the non-urban roads in Israel. The improvements considered were implemented by the National Transport Infrastructure Company in the framework of a black-spots' treatment project, over the years 2007 2009.

Methods In the study, information on about two hundred locations treated was collected, where about thirty treatment types were found suitable for evaluation. For each treatment site, accident changes were examined using after-before comparisons, accounting for changes that had occurred in the comparison-group sites and for a regression-to-the-mean. For sites with a similar treatment a weighted value of the efficiency index was produced. Both the significance of findings and their comparability with international and previous local experience were examined to assign a final list of safety effects.

Results Finally, accident reduction factors were obtained for 19 types of road infrastructure improvements. Applying those, we estimated that the black-spots' treatment project was associated with an average annual saving of 224 injury accidents and 531 total accidents, having a tangible economic value. Conclusions Most values of safety effects observed under Israeli conditions were in line with the international knowledge, while for some and especially combined treatments, the international experience is lacking. The updated accident reduction factors are applicable for the efficiency assessment of future investments in a safer road infrastructure.
\end{abstract}

Keywords Road safety · Road infrastructure · Treatment . Safety efficiency $\cdot$ Accident reduction factor

V. Gitelman $(\bowtie) \cdot$ R. Carmel $\cdot$ F. Pesahov

Ran Naor Road Safety Research Center, Israel Institute of

Technology, Haifa 32000, Israel

e-mail: trivica@technion.ac.il

\section{Introduction}

Road infrastructure improvements play an essential role in increasing the safety level of a road network [4, 20]. Recognizing the global burden of road crashes throughout the world [23], there is a consensus in the road safety literature that many crashes can be prevented by implementing effective road safety measures [20].

In Israel, the National Transport Infrastructure Company (NTIC) is responsible for maintenance, upgrading and extension of the rural (non-urban) road network, which currently comprises over $4,500 \mathrm{~km}$ of roads. According to recent accident statistics, annually, over 150 fatal, about 400 serious and some 3,000 slight accidents occur on the rural road network, accounting, respectively, for 55,30 and $25 \%$ of the total accident figures in the country [3].

Every year, the NTIC carries out various road infrastructure improvements on the existing rural road network. Mostly, such improvements are implemented at hazardous locations - road sections and junctions, which are associated with higher accident numbers and sometimes are termed "black-spots". The purpose of infrastructure improvements is to enhance the level of safety of the sites treated.

To examine the impact of implemented road infrastructure improvements and to provide a basis for better fitting of future treatments, safety efficiency of the treatments applied needs to be assessed. In this context, "safety efficiency" of an infrastructure measure is seen as its contribution to reducing accident frequency and/or severity at the sites treated, following the treatment. Those are typically estimated by means of "after-before" evaluation studies which consider accident statistics 'after' the treatment compared to the 'before' period, where the analysis should account for a number of confounding factors $[7,8]$.

Concerning the percentage of accident reduction following a treatment, the term 'safety effect' is usually applied in the 
road safety literature [21, 7]. Recently, the terms of crash reduction factor (CRF) and accident ${ }^{1}$ modification factor (AMF) were introduced to reflect the level of effectiveness of a treatment $[17,13]$, where both terms present different ways of expression. While CRF shows a percentage of accident reduction (e.g. $15 \%$ ), AMF provides an expected proportional reduction in accident frequency following the treatment, e.g. $1-15 / 100=0.85$.

Internationally, a large number of publications on road safety are devoted to the observed effects of safety treatments. More than a decade ago, the findings of various studies began to be considered and arranged on a systematic basis. As a result of such processes, reports and books with summary values of safety effects were published, such as Elvik \& Vaa [5] and later Elvik et al. [7], Harkey et al. [13], Austroads [1, 2]. While Elvik et al. [7] provides the results of meta-analyses of the research findings coming from around the world, the two other sources are more focused on findings relevant to the U.S. and Australia (and New Zealand). A review of major sources with values of safety efficiency of road safety measures can be also found in Yannis et al. [25], who considered current practices for road safety assessment worldwide gathered in various handbooks, manuals, research projects and other international reports.

When local experience concerning the effects of certain safety-related measure is lacking, it is common practice today to apply the international findings. However, as local road and traffic conditions are not identical to those of other countries, typically, it is preferable to apply the local values of safety effects, i.e. those attained by the evaluation studies performed in the country, when available $[12,24]$.

In Israel, a number of studies evaluating safety effects of road infrastructure improvements were carried out in the past. A first study that estimated such effects on a systematic basis was commissioned by the Ministry of Transport more than a decade ago. That study developed a uniform methodology for evaluating potential safety effects of projects on road infrastructure improvements, collected data on road infrastructure improvements performed on the Israeli road network through the 1990s, conducted the evaluations of more than thirty treatment types and produced twenty estimates of safety effects in local conditions [8]. The values of safety effects were adopted in the guidelines on the appraisal of transport projects in Israel [19]. Later on, another study was carried out for the NTIC which examined the safety effects of infrastructure improvements implemented on rural Israeli roads during the middle of the 2000s. In that study, updated estimates of safety effects were obtained for thirteen treatment types [10].

Over the years 2007-2009, in the framework of a blackspots' treatment project, the NTIC implemented many improvements in the infrastructure of non-urban roads. The

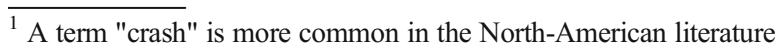

purpose of the study presented in this paper was to examine safety efficiency of road infrastructure improvements applied in 2007-2009, including estimation of accident savings associated with the black-spots' treatment project and their economic value.

\section{The study's database}

The data needed for "after-before" evaluations of road infrastructure improvements are not readily available. Usually, considerable efforts are required to get consistent and reasonably detailed data $[8,14]$. Thus, the first step of the current study dealt with collecting and arranging information on the infrastructure improvements implemented in 2007-2009. Based on the information sources provided by the NTIC, such as the lists of treatment sites according to years and various working reports, a study's database was established. In the database, the information received from various sources was cross-checked, in order to determine, for each treatment considered, the details requested for further analysis, i.e. the location of the site treated, types of infrastructure improvements applied and the periods of the project performance (road-works) on the road.

Furthermore, data checking and completion towards the analysis were conducted. Using the database information, multiple data checks and supplements were applied as well as classifications of the infrastructure improvements and of the sites treated were carried out, in order to define the types of infrastructure improvements suitable for safety evaluation. For each treatment type to be considered, a list of sites treated in this manner presenting the "treatment group", the sites to be used as a comparison-group, accident types to be examined and the periods of analysis, were assigned.

In total, the study's database accumulated information on about one hundred and fifty junctions/interchanges and about fifty road sections that were treated over the years 2007-2009. Following data checks, supplements and classifications, it was decided that the examination of accident changes due to infrastructure improvements would relate to twenty nine treatment types implemented at 135 sites, including: eleven types of infrastructure improvements on road sections applied at 35 sites; thirteen types of junction treatments applied at 91 sites; and five types of interchange treatments applied at nine sites. The types of road infrastructure improvements considered by the study are detailed in Tables 2-3. They concerned, for example, upgrading a single-carriageway to a dualcarriageway road section; barrier installation - building a rigid median, on a single-carriageway road section; various treatments of existing barriers, resurfacing, road marking and signing of road sections; building a roundabout or traffic lights' installation at a junction; replacing traffic signal lenses with light emitting diodes (LEDs) at a signalized junction; 
minor geometric realignment as well as pavement, signing or barrier treatments at a junction (including junctions belonging to interchange areas).

It should be noted that some of the treatments considered are combined, i.e. comprising a number of infrastructure improvements at the same location. For example, it can be roadside barrier treatments with signing and road marking improvements, on a road section, or resurfacing together with replacing traffic signal lenses with LEDs, at a signalized junction. For such a treatment, the estimated safety effect will reflect a combined impact of all the infrastructure changes applied, without the possibility of further subdivision into separate components.

\section{Method of analysis}

The method for evaluating safety effects of road infrastructure improvements was developed by a previous Israeli study [8]. Today, it is widely accepted that the estimation of a safety effect should satisfy the criteria of correct safety evaluation $[24,7,16,20]$. Due to the fact that safety studies are observational (non-experimental), there are confounding factors, which influence the accident occurrences and, therefore, should be accounted for in the estimation of a real safety effect of the treatment. The nature of confounding factors, which should be accounted for in the evaluation of safety effects, has been explained in detail by Hauer [15], Elvik et al. [7], HSM [16]. To properly quantify the effect of a treatment, a simple before/after accident comparison is not correct. It is necessary to compare the accident situation with the treatment ("after") with the situation that would have existed had the treatment not been applied. Practically, the evaluation should account for the uncontrolled environment, e.g. general (long-term) accident trends, exogenous changes in traffic volumes, and for the selection bias (regression-to-the-mean) if relevant.

The determination of what situation would have occurred without the treatment is a critical phase of the process and is performed in two steps:

* estimation of the correct before value (of accidents);

* estimation of the correct after value (of accidents) without the treatment.

The first point accounts for the selection bias, the second point - for the uncontrolled environment. The Empirical Bayes method constitutes an effective instrument for the first point $[22,16]$, where a correction of "before" accident numbers should preferably be performed with the help of safety performance functions developed for certain types of sites. A safety performance function is a multivariate model, which establishes a relationship between accidents and traffic flows and (optionally) other road characteristics of the road sites considered.

For the second point (the corrected value of accidents without the treatment), a comparison group can be used. This approach relies on the assumption that the changes in the number of accidents in the comparison group correctly predict the changes that would have occurred at the treatment sites in the absence of treatment. Ideally, the comparison group should be large (to strengthen the significance of findings), demonstrate a similarity with the treatment group from the engineering viewpoint, and a certain similarity with the treatment group from the viewpoint of accident changes in the past $[15,11]$.

In the current study, the evaluation of a treatment effect, at each site, was conducted by means of the odds-ratio of accident numbers observed at treated and comparison-group sites, in the before and after periods, as follows:

$\theta_{i}=\left[X_{a} / X_{m}\right] /\left[C_{a} / C_{b}\right]$

\section{where:}

$\theta \mathrm{i} \quad$ The estimate of the safety effect observed at site $i$

$X_{a}$ the number of accidents observed at the treatment site in the "after" period

$\mathrm{X}_{\mathrm{m}}$ the modified (i.e. accounting for a selection bias) number of accidents at the treatment site in the "before" period $\left(\mathrm{X}_{\mathrm{b}}\right)$

$\mathrm{C}_{\mathrm{a}}$ the number of accidents in comparison group sites in the "after" period

$\mathrm{C}_{\mathrm{b}}$ the number of accidents in comparison group sites in the "before" period.

To be applied, formula [1] requires one of two conditions to be present: (a) equal duration of "before" periods and equal duration of "after" periods for the treatment site and the comparison group; or (b) equal duration of "before" and "after" periods for the treatment site and the same for the comparison group.

When a number of sites are treated in the same manner, a weighted effect of the treatment, across all the sites considered, should be estimated. Such a pooling of separate results into one value also helps in enhancing the statistical power of the final estimate, which will rely on a larger number of accidents considered.

The weighted mean effect (WME) based on a set of sites is estimated by

$W M E=\exp \left(\frac{\sum_{i} w_{i} \ln \left(\theta_{i}\right)}{\sum_{i} w_{i}}\right)$ 


$$
w_{i}=\frac{1}{\operatorname{VAR}\left(\ln \left(\theta_{i}\right)\right)}=\frac{1}{\frac{1}{X_{a}^{i}}+\frac{1}{X_{b}^{i}}+\frac{1}{C^{i}{ }_{a}}+\frac{1}{C^{i}{ }_{b}}}
$$

where

$\mathrm{W}_{\mathrm{i}}$ - statistical weight of the estimate for site $i$,

$\mathrm{X}_{\mathrm{a}}^{\mathrm{i}}$ - the number of accidents observed at treatment site $i$, in the "after" period,

$\mathrm{X}_{\mathrm{b}}^{\mathrm{i}}$ - the number of accidents at treatment site $i$, in the "before" period,

$\mathrm{C}_{\mathrm{a}}^{\mathrm{i}}$ - the number of accidents in comparison group (for site i), in the "after" period,

$\mathrm{C}_{\mathrm{b}}^{\mathrm{i}}$ - the number of accidents in comparison group (for site $i$ ), in the "before" period,

$\exp$ is the exponential function, $\ln$ is the logarithm.

The confidence interval of WME is given by

$$
\left(W M E \times \exp \left(\frac{z_{\frac{\alpha}{2}}}{\sqrt{\sum_{i} w_{i}}}\right), W M E \times \exp \left(\frac{z_{1-\frac{\alpha}{2}}}{\sqrt{\sum_{i} w_{i}}}\right)\right),
$$

where $100(1-\alpha) \%$ is the confidence level (95\% is usually accepted).

The applicable value of the safety effect - safety efficiency index associated with the treatment (in percents), is calculated as (1-WME)*100. The accident reduction is significant when the whole WME confidence interval is below one. Where the WME confidence interval includes one, the result is not significant but a decreasing or increasing accident trend can be indicated depending on the WME-value. In addition, where the average value of the efficiency index is below $5 \%$, no practical meaning can be attributed to such a result and, thus, a "no change" effect is stated. Finally, in the case where the data sample is insufficient and a very wide confidence interval is obtained for the WME, "no result" is indicated.

In the current study, for each treatment type, the estimation of safety effects was conducted using three accident types: (a) injury accidents, (b) severe (i.e. serious + fatal) accidents and (c) total accidents which are the sum of injury accidents and "general with casualties" accidents. It should be noted here that in Israel two types of accident files are collected by the police and produced by the Central Bureau of statistics (CBS): (a) injury accident file, with cases investigated by the police examiners, and (b) "general with casualties" accident file, with cases reported to the police but not investigated. The first file includes all injury severity levels: fatal, serious and slight, where slight injury accidents satisfy certain selection criteria concerning the time passed since the occurrence and accident participants. The second file includes cases with slight injuries only (not hospitalized), which did not satisfy the selection criteria of the "injury" file. The first file serves as a basis for the official accident and injury figures in the country.
However, as the amount of records in the second file versus the first file presents a $78 \%$ to $22 \%$ relation [3], it is a common demand today to conduct accident analyses involving both files.

In addition to the three accident types mentioned above, for some treatment types, particular types of target accidents were examined, such as pedestrian accidents or head-on collisions, which were assigned in accordance with the topic of infrastructure improvements applied. However, in all such cases the results were not significant due to insufficient accident data.

As comparison-group sites were considered: for road section treatments - total single- or dual-carriageway rural road sections (depending on the type of treatment site); for junctions' and interchanges' treatments - all interurban junctions. Concerning junctions, the use of more detailed comparison groups, such as signalized and non-signalized junctions depending on the type of treatment site, was examined but found to be not realizable in the current study, due to the data problems revealed in the CBS injury files, with regard to the correct coding of junction types.

Regarding the period of analysis, for each treatment site, we aspired to apply a three-year before and a three-year after period. The periods were derived relating to the beginning and the end of the roadwork performance at the sites treated. For treatments applied in 2009, a shorter than three-year after period was defined as accident files available for the study were limited by 2011. The consideration of total accidents (a sum of two files, "injury accidents"+"general with casualties") was possible starting from 2005 only as for previous years the "general with casualties" file is not available. As a result, in relevant cases, the before period for total accidents was limited to two years. In any case, the data periods derived for the comparison-group sites were identical to those of the sites treated. The accident counts at the sites treated, according to the treatment types examined by the study, are given in Appendix.

To consider a possible regression-to-the-mean effect, for each treatment type, the evaluation was conducted twice, i.e. without and with a correction of the "before" accident numbers, using the values produced by safety performance functions. Safety performance functions for estimating the expected number of accidents at certain types of sites, based on the exposure (annual average daily traffic), were previously developed in Israel for single- and dual-carriageway road sections as well as for various types of junctions [9]. They enable to provide estimates for injury accidents, in total and subdivided by accident severity. Thus, in the current study, the estimates of efficiency indices with a correction due to regression-to-the-mean, were obtained for injury and severe accidents but not for total accidents (i.e. injury + "general with casualties" accidents), for which the correction tools are lacking. Moreover, such repeated 
evaluations were applied to road section treatments only, where they were considered as a sensitivity analysis of the results. As to accident changes observed at junctions and interchanges, additional corrections, using safety performance functions, were not applied due to evident problems experienced with the comparison-group accident data that diminished the importance of a further correction due to possible selection bias.

\section{Evaluation results}

\subsection{Examples}

As explained above, for each treatment type (infrastructure improvement) a percentage of accident change in the treatment sites in the "after" versus the "before" period, accounting for the changes that occurred in the comparison-group, was estimated. The accident changes observed at similarly treated sites were weighted to obtain a summary value - the efficiency index, according to treatment type, for which both an average value and a confidence interval (at 0.05 confidence level) were estimated.

Table 1, a-c, provides examples of estimating efficiency indices for selected treatment types such as: (a) upgrading a single-carriageway to a dual-carriageway road section, (b) barrier installation - building a rigid median, on a single-carriageway road section, (c) resurfacing and replacing lenses by LEDs, at a signalized junction. Fig. 1, a-c, illustrates the accident numbers observed at the treatment and comparison sites, in each example, and demonstrates the values of efficiency indices and their confidence intervals.

The upgrading a single-carriageway to a dual-carriageway road section was applied on two road sections: (1) road No $70, \mathrm{~km} 66-77$, where the road-works took place in 2007-2009; (2) road No 85, km 24-25, with actual roadworks in 2007-2008. The before period for both sites was 2004-2006, the after period was 2010-2011 for road No 70, 2009-2011 - for road No 85; accidents numbers for comparison-group sites (all single-carriageway road sections on the road network) were derived for similar time periods. As becomes clear from Table 1-a and Fig. 1-a, this treatment was associated with a consistent accident reduction in all accident types, which was significant for injury and total accidents and indicated a reduction trend for severe accidents. A sensitivity analysis accounting for the selection bias did not change the essence of the results, yet provided slightly lower values of the effects for injury and severe accidents, i.e. a $32 \%$ reduction in injury accidents instead of $34 \%$, and a reduction trend in severe accidents with a mean value of $17 \%$ instead of $22 \%$.

In the second example, barrier installation - building a rigid median, on a single-carriageway road section, was implemented at four road sections, each of 3-4 km in length, between 2007 and 2009. For two sections, the before period was 2004 2006, for others 2005-2007, where after periods were 2008-

Table 1 Examples of estimating efficiency indices for selected treatment types

\begin{tabular}{lcl} 
(a) Upgrading a single-carriageway to a dual-carriageway road section & \\
Accident type & Efficiency index, $95 \%$ confidence interval & \\
Injury accidents & $-34 \%[-49 \% ;-13 \%]$ & Meaning \\
Severe accidents & $-22 \%[-62 \% ;+63 \%]$ & Reduction \\
Total accidents & $-31 \%[-41 \% ;-19 \%]$ & Reduction trend \\
Injury accidents, accounting for selection bias & $-32 \%[-48 \% ;-11 \%]$ & Reduction \\
Severe accidents, accounting for selection bias & $-17 \%[-60 \% ;+74 \%]$ & Reduction \\
(b) Barrier installation - building a rigid median, on a single-carriageway road section & Reduction trend \\
Accident type & Efficiency index, CI & Meaning \\
Injury accidents & $-61 \%[-74 \% ;-42 \%]$ & Reduction \\
Severe accidents & $-71 \%[-89 \% ;-20 \%]$ & Reduction \\
Total accidents & $-23 \%[-40 \% ;-2 \%]$ & Reduction \\
Injury accidents, accounting for selection bias & $-50 \%[-68 \% ;-24 \%]$ & Reduction \\
Severe accidents, accounting for selection bias & $-49 \%[-83 \% ;+53 \%]$ & Reduction trend \\
(c) Resurfacing and replacing lenses by LEDs, at a signalized junction & \\
Accident type & Efficiency index, CI \\
Injury accidents & $+8 \%[-32 \% ;+72 \%]$ \\
Severe accidents & $+17 \%[-86 \% ;+868 \%]$ & Meaning \\
Total accidents & $+7 \%[-22 \% ;+46 \%]$ & Increasing trend \\
\hline
\end{tabular}

${ }^{\text {a }}$ No result (insufficient data) 
Fig. 1 Accident numbers observed at the treatment and comparison sites, and evaluation results, in each example. Comments: before- $T$ and after- $T$ represent total accident numbers at the treatment sites, in before and after periods; before- $C$ and after- $C$ represent similar accident numbers at the comparison-group sites; $S B$ - estimates accounting for a selection bias

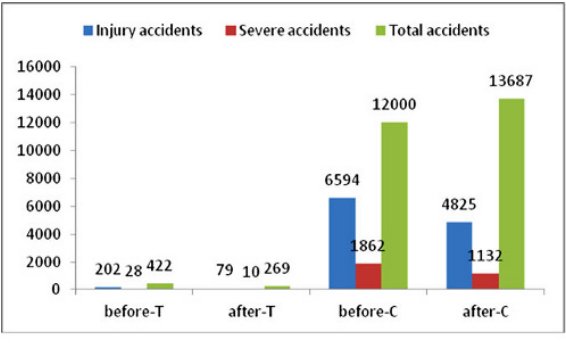

Accident numbers observed

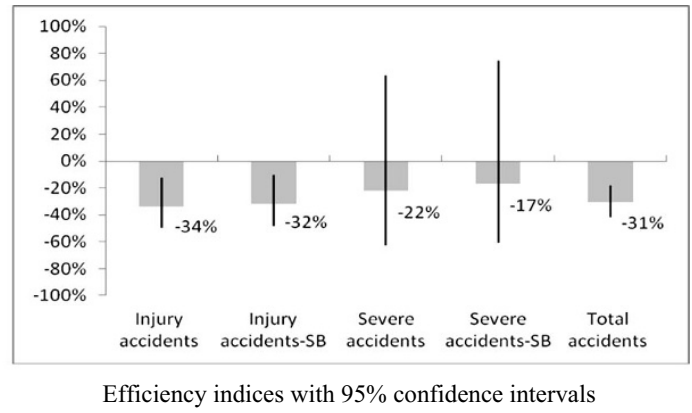

Efficiency indices with $95 \%$ confidence intervals (a) Upgrading a single-carriageway to a dual-carriageway road section

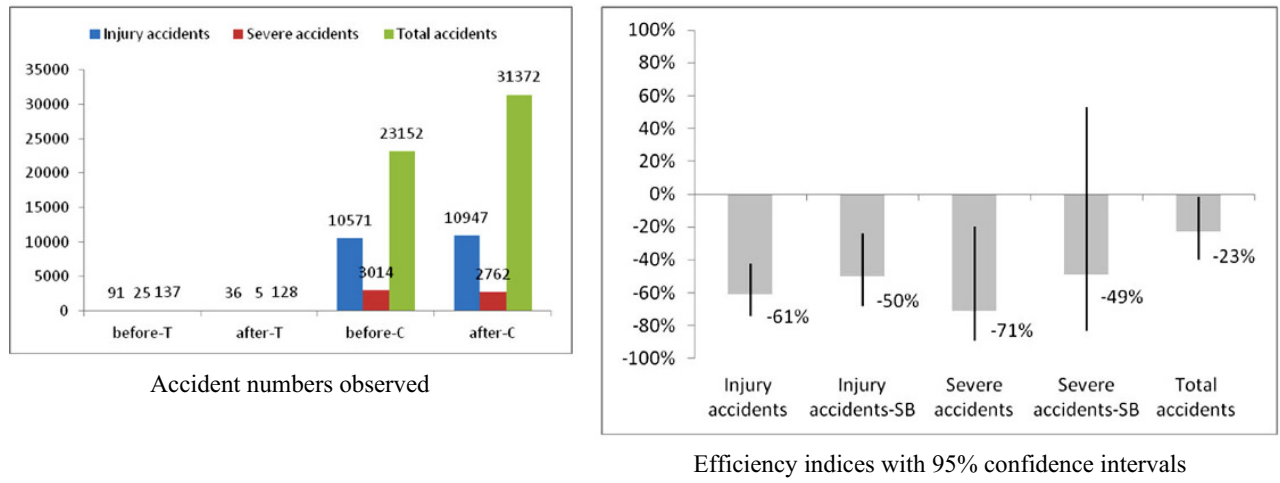

(b) Barrier installation - building a rigid median, on a single-carriageway road section

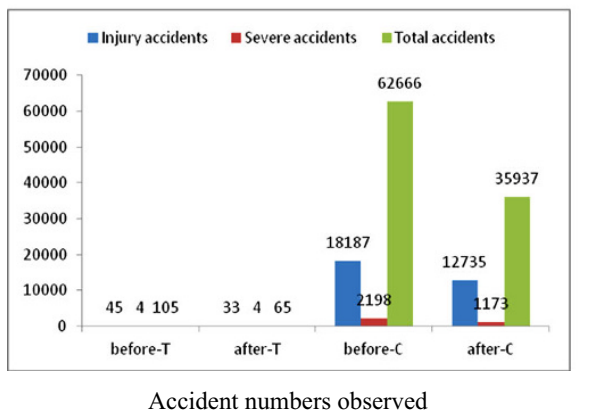

(c) Resurfacing and replacing lenses by LEDs, at a signalized junction

2010 or 2009-2011, respectively. The comparison-group sites were single-carriageway road sections on the whole road network, for which accident data were derived for similar time periods. Following this treatment, significant accident reductions were observed in all accident types (see Table 1-b and Fig. 1-b). Accounting for a selection basis slightly diminished the effect observed for injury accidents, from a $61 \%$ to a $50 \%$ reduction in accidents, where for severe accidents the reduction became insignificant.

At the same time, in some cases, following the infrastructure improvements, positive accident changes were not found. For example, in the case presented in Table 1-c and Fig. 1-c, pavement resurfacing and replacing lenses by LEDs were applied at three signalized junctions. The treatment was applied in 2008 or at the beginning of 2009. Hence, 2005-2007 or 2006-2008 were considered as before periods, and 2009-
2011 (or a shorter period from April 2009 till the end of 2011) as an after period. The comparison-group in this case included all interurban junctions, for which accident data were derived for similar time periods. Following this treatment, no positive accident changes were found but an increasing trend was observed (yet, not significant) in injury and total accidents, where for severe accidents no result was stated due to insufficient data.

\subsection{Summary of findings and their further examinations}

Tables 2-3 summarize the evaluation results obtained for road sections and junctions/interchanges, respectively. The significant results are given in numbers, where other results are described verbally. For cases where a sensitivity analysis was carried out, the results with a correction due to selection 
bias are shown. Figs. 2-3 provide a visual presentation of the significant results - the efficiency indices and their confidence intervals, for treatments applied on road sections and junctions/interchanges, respectively.

It can be seen that significant accident reductions following road infrastructure improvements were observed in part of the cases examined, and not always both in injury and total accidents. More significant results were received for road sections' than for junction/interchange treatments. To a certain extent, this could be due to statistical reasons, i.e. bigger samples of accident numbers accumulated, in the current analysis, for road section groups compared to junction groups. In all the cases considered, significant results were not obtained for severe accidents, mostly due to insufficient samples of such accidents at the sites treated.

Once the efficiency index is significant and demonstrates an accident reduction, it can be accepted as the safety effect associated with the treatment type. However, to ascertain that the new findings are reasonable and sufficiently strong to serve as a basis for cost-benefit evaluations of the potential projects [8], they should be compared with previous experience. For example, if the new finding for a certain treatment type is conflicting with the values previously reported, e.g. it is too high or indicates an increase in accidents whereas accident reductions were generally observed in other countries, such a result should be applied with caution. In general, we believe that new safety effect values can be recommended for further application without reservation where those are significant and also resemble the international expertise and/or previous results. Similarly, OECD [22] recommends considering a variation in various study findings, with regard to certain treatment types, in order to decide whether the results are transferable.

Thus, the current study's findings were compared with values coming from the international literature and from previous local evaluation studies that considered similar infrastructure improvements. As major sources of safety effect values coming from the international experience we used Elvik et al. [7], HSM [16], Austroads [1, 2]. The results of previous local evaluation studies were taken from $[8,10]$.

Table 4 demonstrates examples of detailed examinations of safety effects of the road infrastructure improvements applied on road sections. For each of the treatment types associated with a significant accident reduction, in the current study, detailed values of safety effects were collected from other sources. It was found that the new estimates generally belong to the range of the values

Table 2 Summary of evaluation results for treatments on road sections: efficiency indices and their $95 \%$ confidence intervals

\begin{tabular}{|c|c|c|c|}
\hline Type of infrastructure improvement (\#) & Injury accidents & $\begin{array}{l}\text { Severe } \\
\text { accidents }\end{array}$ & Total accidents \\
\hline Upgrading a single-carriageway to a dual-carriageway road section (2) & $\begin{array}{l}-32 \%[-48 \% \\
-11 \%]\end{array}$ & $\begin{array}{l}\text { Reduction } \\
\text { trend, } n s\end{array}$ & $\begin{array}{l}-31 \%[-41 \% \\
-19 \%]\end{array}$ \\
\hline Building a median on a road section crossing an urban area (2) & No change & - & $\begin{array}{l}-53 \%[-66 \% \\
-37 \%]\end{array}$ \\
\hline Barrier installation - building a rigid median, on a single-carriageway road (4) & $\begin{array}{l}-50 \%[-68 \% \\
-24 \%]\end{array}$ & $\begin{array}{l}\text { Reduction } \\
\quad \text { trend, } n s\end{array}$ & $\begin{array}{l}-23 \%[-40 \% \\
-2 \%]\end{array}$ \\
\hline A combined treatment: barriers, road marking/signing, on a single-carriageway road (4) & Increasing trend, $n s$ & - & $\begin{array}{l}-13 \%[-27 \% ;+ \\
3 \%]^{*}\end{array}$ \\
\hline A combined treatment: barriers, road marking/signing, on a dual-carriageway road (3) & No change & No change & $\begin{array}{l}-14 \%[-22 \% \\
\quad-6 \%]\end{array}$ \\
\hline $\begin{array}{l}\text { A combined treatment: resurfacing, road marking, barriers' treatment, on a single- } \\
\text { carriageway road (6) }\end{array}$ & $\begin{array}{l}-16 \%[-29 \% \\
-1 \%]\end{array}$ & No change & $\begin{array}{l}-20 \%[-28 \% \\
-11 \%]\end{array}$ \\
\hline $\begin{array}{l}\text { A combined treatment: resurfacing, road marking, barriers' treatment, on a dual-carriageway } \\
\text { road (6) }\end{array}$ & $\begin{array}{l}-23 \%[-30 \% \\
\quad-16 \%]\end{array}$ & No change & No change \\
\hline A combined treatment: barriers, resurfacing, shoulders, on a single-carriageway road (5) & $\begin{array}{l}-12 \%[-23 \% \\
-0 \%]\end{array}$ & $\begin{array}{l}\text { Increasing } \\
\quad \text { trend, } n s\end{array}$ & $\begin{array}{l}-19 \%[-25 \% \\
-13 \%]\end{array}$ \\
\hline A combined treatment: signs, pavement, shoulders, on a single-carriageway road (1) & Reduction trend, $n s$ & $\begin{array}{l}\text { Reduction } \\
\quad \text { trend, } n s\end{array}$ & Reduction trend, $n s$ \\
\hline $\begin{array}{l}\text { A combined treatment: resurfacing, crash cushions' installation, barriers' treatment, on a } \\
\text { dual-carriageway road (1) }\end{array}$ & No change & No change & $\begin{array}{l}-17 \%[-24 \% \\
-11 \%]\end{array}$ \\
\hline $\begin{array}{l}\text { Pavement treatments, including road marking, raised markers, on a single-carriageway road } \\
\text { (1) }\end{array}$ & No change & $\begin{array}{l}\text { Reduction } \\
\quad \text { trend, } n s\end{array}$ & $\begin{array}{l}-23 \%[-38 \% \\
-5 \%]\end{array}$ \\
\hline
\end{tabular}

Notes to Table 2: \# number of sites treated; 35 road sections in total. The numerical results presented are significant at 0.05 confidence level; $*$ significant at 0.1 level; $n s$ - not significant

"-" means no result (insufficient data); "no change" indicates that average value of the efficiency index is below $5 \%$ 
Table 3 Summary of evaluation results for treatments at junctions and interchanges: efficiency indices and their $95 \%$ confidence intervals

\begin{tabular}{|c|c|c|c|}
\hline Type of infrastructure improvement (\#) & Injury accidents & Severe accidents & Total accidents \\
\hline \multicolumn{4}{|l|}{ At junctions } \\
\hline Building a roundabout (9) & $-52 \%[-71 \% ;-21 \%]$ & - & Reduction trend, $n s$ \\
\hline Traffic lights' installation (14) & $-29 \%[-49 \% ;-2 \%]$ & - & $+46 \%[+17 \% ;+81 \%]$ \\
\hline Minor geometric realignment at a signalized junction (26) & No change & No change & $+13 \%[+2 \% ;+25 \%]$ \\
\hline Signing arrangement at junction (4) & No change & - & $-36 \%[-52 \% ;-16 \%]$ \\
\hline Replacing lenses by LEDs, at a signalized junction (11) & Reduction trend, $n s$ & - & Increasing trend, $n s$ \\
\hline Resurfacing junction and replacing lenses by LEDs (3) & Increasing trend, $n s$ & - & Increasing trend, $n s$ \\
\hline Resurfacing and barrier treatments at a signalized junction (7) & $-20 \%[-38 \% ;+2 \%]^{*}$ & Reduction trend, $n s$ & $-19 \%[-28 \% ;-9 \%]$ \\
\hline Shoulder treatments and replacing lenses by LEDs (2) & No change & - & Increasing trend, $n s$ \\
\hline $\begin{array}{l}\text { Changes in traffic signal program and replacing lenses by LEDs, } \\
\text { at a signalized junction (2) }\end{array}$ & - & - & Increasing trend, $n s$ \\
\hline $\begin{array}{l}\text { Crosswalks' arrangement and signing treatment, at a signalized } \\
\text { junction (1) }\end{array}$ & Reduction trend, $n s$ & - & Increasing trend, $n s$ \\
\hline Barrier treatments, at a signalized junction (9) & $-28 \%[-43 \% ;-9 \%]$ & Reduction trend, $n s$ & $-11 \%[-20 \% ; 0 \%]^{*}$ \\
\hline Pavement treatments, at a signalized junction (2) & $-50 \%[-68 \% ;-20 \%]$ & Reduction trend, $n s$ & $-25 \%[-44 \% ;+2 \%]^{*}$ \\
\hline $\begin{array}{l}\text { Installing pedestrian fences and replacing lenses by LEDs, } \\
\text { at a signalized junction (1) }\end{array}$ & Reduction trend, $n s$ & - & Increasing trend, $n s$ \\
\hline \multicolumn{4}{|l|}{ On interchanges } \\
\hline Realignment of junction on the interchange (1) & - & - & Increasing trend, $n s$ \\
\hline Building roundabouts on the interchange (1) & $-72 \%[-92 \% ;-5 \%]$ & - & Reduction trend, $n s$ \\
\hline Barrier treatments (2) & Increasing trend, $n s$ & - & $-28 \%[-42 \% ;-10 \%]$ \\
\hline Traffic signal installation at a junction (1) & Reduction trend, $n s$ & - & Reduction trend, $n s$ \\
\hline Ramps' resurfacing (4) & $-23 \%[-38 \% ;-5 \%]$ & Reduction trend, $n s$ & Increasing trend, $n s$ \\
\hline
\end{tabular}

Notes to Table 3: \# number of sites treated; 91 junctions and 9 interchanges, in total. The numerical results presented are significant at 0.05 confidence level; * significant at 0.1 level; $n s$ - not significant

"-" means no result (insufficient data); "no change" indicates that average value of the efficiency index is below $5 \%$

observed, for similar treatments, in other studies and, therefore, can be judged as suitable for further application. At the same time, the majority of treatments estimated for Israeli conditions were combined, whereas in the international literature typically single treatment values are provided. Thus, certain caution is still required in using the combined treatment effects coming from the current study as those are not supported yet by the international expertise.

Similar examinations of safety effect values of road infrastructure improvements at junctions and interchanges demonstrated that most findings received by the current study were in line with the international results. However, for some treatment types, e.g. "signing arrangement" or "pavement treatments" at junctions, the current study's values were higher than the international equivalent and thus, should be applied with caution. Following traffic lights' installation at junctions, in the current study, an increase in the total accidents was observed. Such a finding, in general, contradicts the international expertise on the subject, yet there are reported evidences on increases in the rear-end collisions following a traffic signal installation, e.g. [13]. Admitting lower quality of accident data coming from the "general with casualties" accident files, in the cases where current evaluation results were different from the common expectations, the findings for total accidents were not included in the final list of estimates recommended for application.

\subsection{Final estimates of the efficiency indices}

Based on the examination of both significance of values received in the safety evaluations and their compatibility with international and previous local experience, accident reduction factors were assigned for 19 types of infrastructure improvements, of which ten were on road sections, six at junctions and three on interchanges. Table 5 presents a final list of safety efficiency indices associated with the infrastructure improvements applied under Israeli conditions. The values in Table 5 relate to injury accidents and total accidents, where (based on the study's results) separate values of accident reduction factors for 
severe accidents or specific accident types cannot be provided.

Due to various reasons, including the small number of treatment sites that served as a basis for the evaluation, a difference observed compared to international values or lack of international values to be compared with, caution is required in using accident reduction factors associated with some treatment types such as: "a combined treatment: resurfacing, crash cushion installation, barrier treatments, on a dual-carriageway road section", "pavement treatments, road marking, raised markers, on a singlecarriageway road section", "pavement treatments at a signalized junction", "signing arrangement at a junction" and all treatment types at interchanges. For such treatment types further monitoring of safety effects is needed in the future.
4.4 Estimating accident savings associated with infrastructure improvements

Table 5 presents the infrastructure improvements which were associated with significant accident reductions following the treatment. This list served as a basis for estimating accident savings attained due to the infrastructure improvement projects applied in 2007-2009 and their economic values. Once a treatment site belongs to an infrastructure improvement associated with a significant accident reduction factor, an estimate of the average accident numbers annually saved following a treatment was provided. Thus, this estimation comprised 19 types of infrastructure improvements which were implemented on 86 sites, including 34 road sections, 45 junctions and 7 interchanges. For each site belonging to those

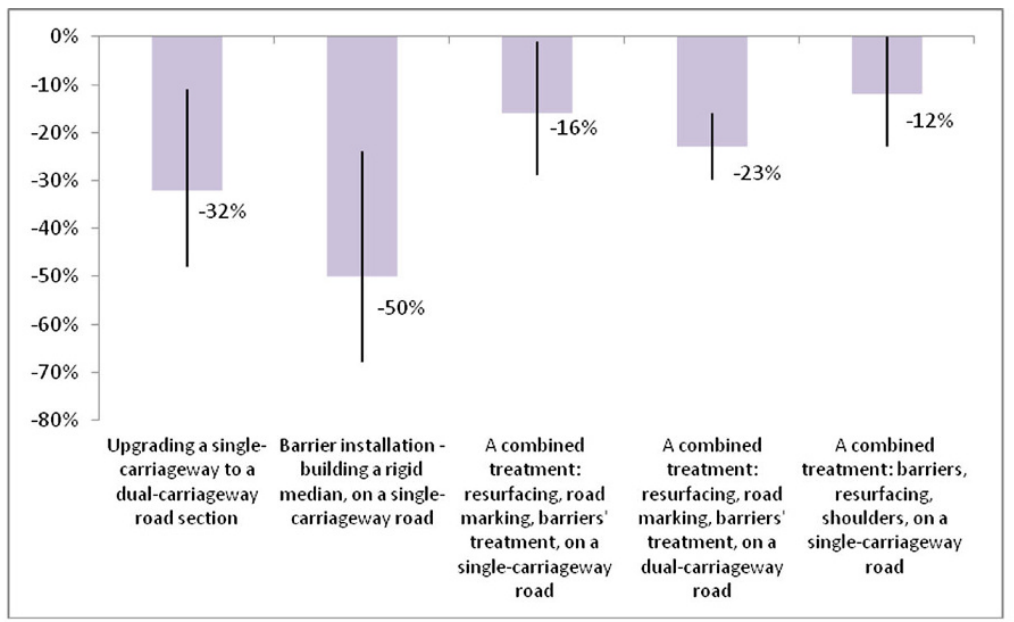

(a) Injury accidents

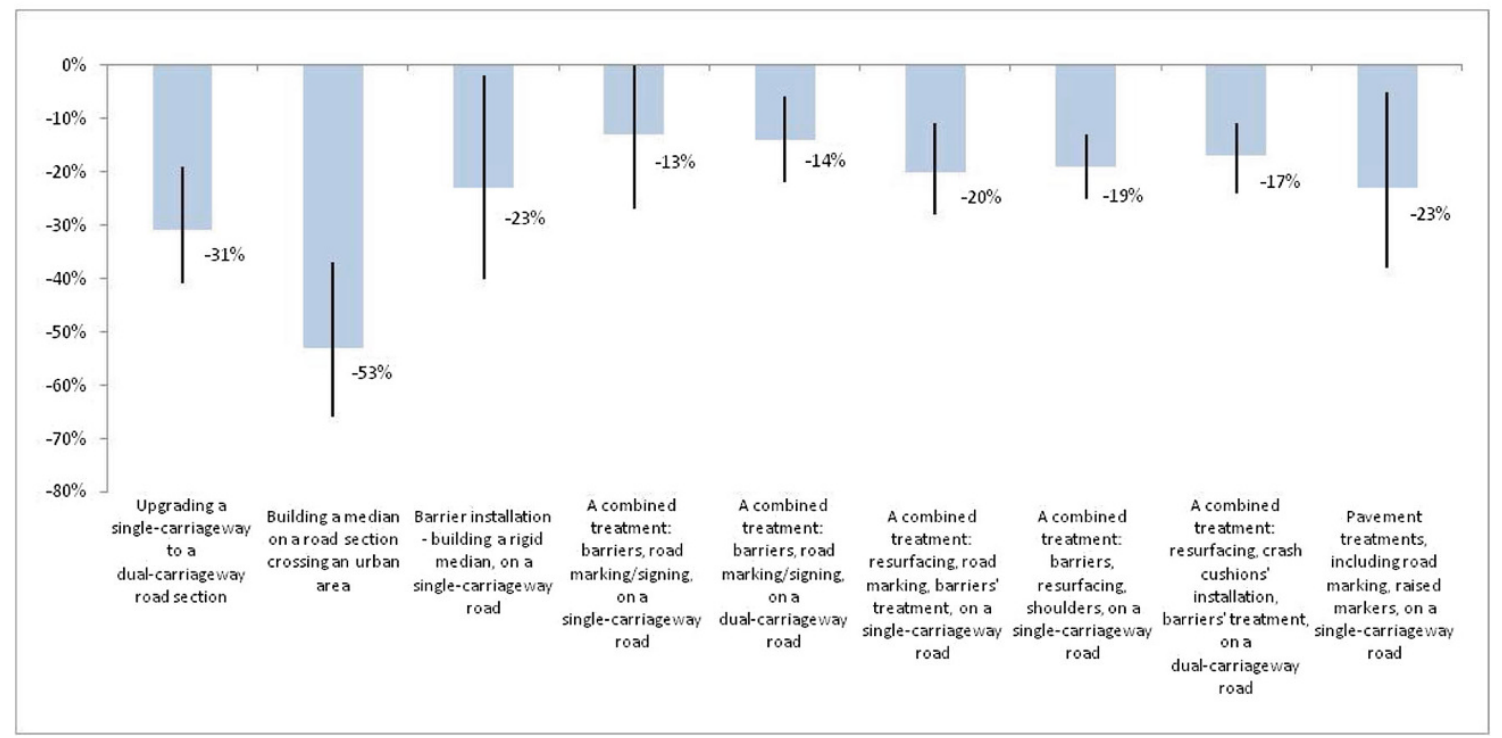

(b) Total accidents

Fig. 2 Significant results of treatments applied on road sections: efficiency indices and their $95 \%$ confidence intervals 
Fig. 3 Significant results of treatments applied at junctions and interchanges: efficiency indices and their $95 \%$ confidence intervals

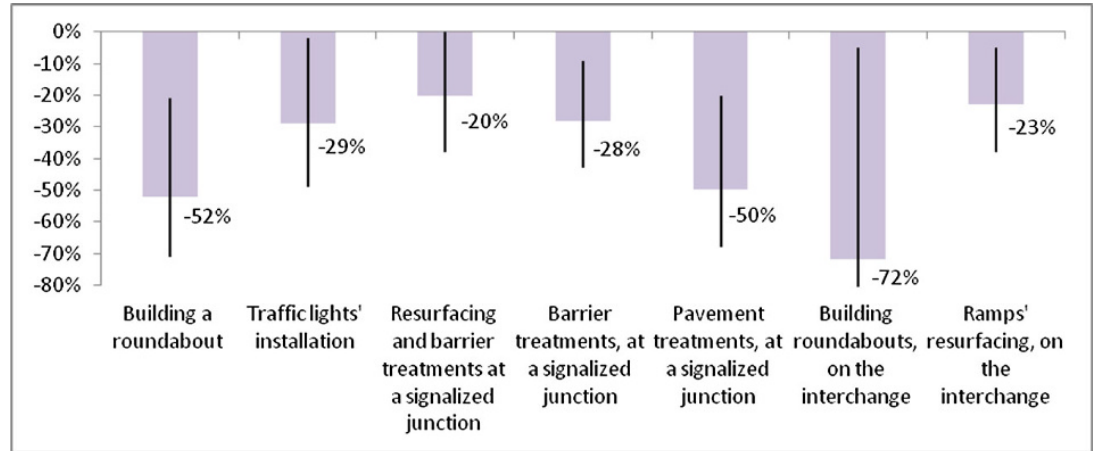

(a)Injury accidents

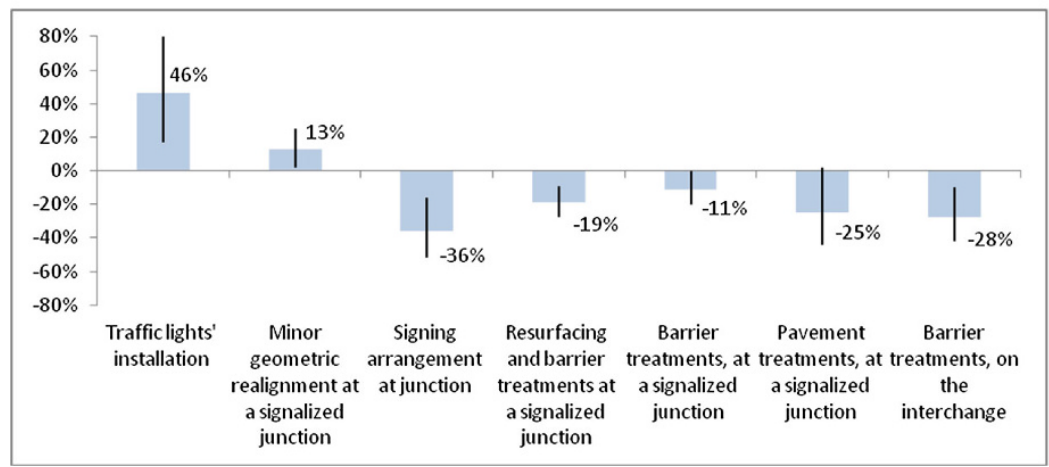

(b)Total accidents infrastructure improvements, the estimation of accidents annually saved included two steps:

(1) the number of accidents expected at the treated site in the "after" period was estimated using the number of accidents at the treatment site in the "before" period $\left(\mathrm{X}_{\mathrm{b}}\right)$ which was multiplied by accident changes observed in the comparison group sites $\left(\mathrm{C}_{\mathrm{a}} / \mathrm{C}_{\mathrm{b}}\right)$ - see notations of formula [1] above;

(2) the number of accidents saved was obtained by multiplying the number of accidents expected by a safety effect associated with the treatment, i.e.(1-WME)*100, with a consequent adjustment accounting for the length of the "after" period (division by the number of years).

Then, the numbers of accidents saved at each site were summarized across the whole list of sites, for certain accident type, to provide a road network figure. The estimated numbers of accidents annually saved due to each treatment type are detailed in Table 5.

The economic values of the accidents saved were estimated by multiplying the numbers by an average accident cost. Based on estimates published by the National Road Safety Authority [18], the cost of an average rural road accident in Israel applied by this study was 182,000 NIS (New Israeli Shekels, where 1 US $\$=4$ NIS).

The evaluation demonstrated (see Table 5) that following the implementation of infrastructure improvements at the black-spots, in 2007-2009:
- On road sections, 153 injury accidents and 427 total accidents were saved annually, where the economic values of those accidents were about 28 and 78 million NIS, respectively;

- At junctions, annually, 54 injury accidents and 89 total accidents were saved, with the economic values of about 10 and 16 million NIS, respectively;

- On interchanges, annually, 17 injury accidents and additional 15 total accidents were saved, where the economic value of each accident saving was about 3 million NIS.

In total, the black-spots' treatment project was associated with an average annual saving of 224 injury accidents and 531 total accidents, whereas the economic value of those accidents close to 41 and 97 million NIS, respectively. The injury accidents saved are equal to an annual saving of 11 fatalities, 36 serious injuries, 555 slight injuries, or 602 casualties, in total.

It is emphasized that the above estimates of savings are based on the infrastructure improvements which brought significant accident reductions, compared to comparison-groups, but do not include accident changes on the remainder of the sites treated for which the treatment effect was not ascertained. It should be noted also that the above estimates reflect average values.

In addition, it should be pointed out that the two estimates provided: of injury accidents saved and of total accidents saved, are not complementary as for some treatment types 
both injury and total accident savings were estimated, thus leaving a possibility for a double-counting of the effects. Those estimates are given mostly for demonstration purposes, i.e. in order to illustrate the scope of accidents definitely saved due to the infrastructure improvements examined in the current study.

\section{Discussion: applicability of the study's findings and future activities}

Having examined the accident changes at the sites treated in 2007-2009, the study provided an update to the list of accident reduction factors associated with road infrastructure improvements on rural roads under local (Israeli) conditions. The final values of safety effects produced by the study are statistically significant and comparable with international and/or previous local experience.

The updated values of safety effects were produced for nineteen types of infrastructure improvements, of which ten were on road sections, six at junctions and three on interchanges. Most values of safety effects obtained for local conditions were in line with the international knowledge. In particular, upgrading a single-carriageway to a dualcarriageway road section, building a roundabout and traffic lights' installation at a junction, were associated with considerable reductions in injury accidents, thus, supporting the results of previous studies on the subject $[7,13,10]$. Concerning a barrier installation in the middle of a single-carriageway road section, a reduction in injury accidents observed in the current study was in line with the effect reported by a previous Israeli study [10], where in the international practice such a treatment of single-carriageway roads is not yet common.

Similarly, other types of barrier treatments applied in Israel, including a replacement of old barriers by new models (those meeting the demands of the European Norms), upgrading barrier ends by means of installation of terminals/crash cushions, adding lacking barrier units, correction of barrier positions, etc. cannot be supported yet by accident modification values coming from the international practice. In this context, the currently available values of safety effects mostly concern safety barrier installation versus no barrier presence or replacing a stiff barrier by a softer type $[7,13]$.

Table 4 Comparison of safety effects of road infrastructure improvements observed in the current study with values coming from international expertise and previous local studies: examples for road section treatments

\begin{tabular}{|c|c|c|c|c|}
\hline $\begin{array}{l}\text { Type of infrastructure } \\
\text { improvement }\end{array}$ & $\begin{array}{l}\text { In current study: } \\
\text { change in injury } \\
\text { accidents }\end{array}$ & $\begin{array}{l}\text { In current study: } \\
\text { change in total } \\
\text { accidents }\end{array}$ & $\begin{array}{l}\text { Results of } \\
\text { previous } \\
\text { local studies } \\
*\end{array}$ & Results from international experience $* *$ \\
\hline $\begin{array}{l}\text { Upgrading a single-carriageway to } \\
\text { a dual-carriageway road section }\end{array}$ & $-32 \%$ sig. & $-31 \%$ sig. & $-40 \%$ sig. & (1) $-51[-65 ;-33]$ \\
\hline $\begin{array}{l}\text { Building a median on a road } \\
\text { section crossing an urban area }\end{array}$ & No change & $-53 \%$ sig. & $\mathrm{n} / \mathrm{a}$ & $\begin{array}{l}\text { (1) Geometric realignment of urban road: }-7[-12 ;-1] \text { (3) } \\
\text { Building a median on urban road: }-45 \text { (medium) }\end{array}$ \\
\hline $\begin{array}{l}\text { Barrier installation - building a } \\
\text { rigid median, on a single- } \\
\text { carriageway road }\end{array}$ & $-50 \%$ sig. & $-23 \%$ sig. & $-29 \% n s$ & $\begin{array}{l}\text { Median barrier installation: (1) }-15[-27 ;-1] \text { (2) } 0.61 \text { (0.1) } \\
\text { (3) }-40 \text { (high) }\end{array}$ \\
\hline $\begin{array}{l}\text { A combined treatment: barriers, } \\
\text { road marking/signing, on a } \\
\text { single-carriageway road }\end{array}$ & $\begin{array}{l}\text { Increasing trend, } \\
\quad n s\end{array}$ & $-13 \%$ near sig. & $-14 \%$ sig. & $\begin{array}{l}\text { (1) Change of barrier to a softer type: }-32[-42 ;-20] \text {; Center- } \\
\text { line marking: }-1[-8 ;+6] \text {; Shoulder-line marking: }-3 \\
\text { [-7;+1]; Signing: }-15[-25 ;-3] \text { (2) Change of barrier to a } \\
\text { softer type: } 0.68(0.1) \text {; Center-line marking: } 0.99(0.06) \text {; } \\
\text { Shoulder-line marking: } 0.97 \text { (0.04); Center- and shoulder- } \\
\text { lines' marking: } 0.76(0.1) \text { (3) Center-line marking: }-30 \\
\text { (low); Shoulder-line marking: }-20 \text { (low) }\end{array}$ \\
\hline $\begin{array}{l}\text { A combined treatment: barriers, } \\
\text { road marking/signing, on a } \\
\text { dual-carriageway road }\end{array}$ & No change & $-14 \%$ sig. & $+24 \%$ sig. & $\begin{array}{l}\text { (1) Change of barrier to a softer type: }-32[-42 ;-20] \text {; Lane } \\
\text { marking: }-18[-51 ;+36] \text {; Shoulder-line marking: }-3[-7 ;+ \\
\text { 1]; Signing: }-15[-25 ;-3](2) \text { Change of barrier to a softer } \\
\text { type: } 0.68(0.1) \text {; Shoulder-line marking: } 0.97(0.04) \text { (3) } \\
\text { Shoulder-line marking: }-20 \text { (low) }\end{array}$ \\
\hline
\end{tabular}

Notes to Table 4: sig. - significant at 0.05 confidence level; near sig. - significant at 0.1 level; $n s$ - not significant; n/a - not available

* From Gitelman et al. [10, 12]

** Sources of international expertise

(1) Elvik et al. [9] - percent of accident reduction with a $95 \%$ confidence interval are presented

(2) HSM [18] - mean estimate and standard error of accident modification factor are presented

(3) Austroads [1,2] - percent of accident reduction with a level of confidence (high, medium, low) are given

From the international and previous local studies changes in injury accidents are presented 
Table 5 Final estimates of safety efficiency indices for rural road infrastructure improvements, received in the current study, and estimation of the number of accidents saved following the treatments

\begin{tabular}{|c|c|c|c|c|}
\hline Type of infrastructure improvement (\#) & $\begin{array}{l}\% \text { of change in } \\
\text { injury accidents }\end{array}$ & $\begin{array}{l}\% \text { of change in } \\
\text { total accidents }\end{array}$ & $\begin{array}{l}\text { Number of injury } \\
\text { accidents annually } \\
\text { saved }\end{array}$ & $\begin{array}{l}\text { Number of total } \\
\text { accidents }{ }^{1} \text { annually } \\
\text { saved }\end{array}$ \\
\hline \multicolumn{5}{|l|}{ Infrastructure improvements on road sections } \\
\hline Upgrading a single-carriageway to a dual-carriageway road (2) & $-32 \%$ & $-31 \%$ & 18.2 & 59.4 \\
\hline Building a median on a road section crossing an urban area (2) & - & $-53 \%$ & - & 26.0 \\
\hline $\begin{array}{l}\text { Barrier installation - building a rigid median, on a single- } \\
\text { carriageway road (4) }\end{array}$ & $-50 \%$ & $-23 \%$ & 11.9 & 14.1 \\
\hline $\begin{array}{l}\text { A combined treatment: barriers, road marking/signing, on a } \\
\text { single-carriageway road (4) }\end{array}$ & - & $-13 \%$ & - & 17.8 \\
\hline $\begin{array}{l}\text { A combined treatment: barriers, road marking/signing, on a } \\
\text { dual-carriageway road (3) }\end{array}$ & - & $-14 \%$ & - & 59.4 \\
\hline $\begin{array}{l}\text { A combined treatment: resurfacing, road marking, barriers' } \\
\text { treatment, on a single-carriageway road (6) }\end{array}$ & $-16 \%$ & - & 15.7 & - \\
\hline $\begin{array}{l}\text { A combined treatment: resurfacing, road marking, barriers' } \\
\text { treatment, on a dual-carriageway road (6) }\end{array}$ & $-23 \%$ & - & 88.5 & - \\
\hline $\begin{array}{l}\text { A combined treatment: barrier treatments, resurfacing, } \\
\text { shoulders, on a single-carriageway road (5) }\end{array}$ & $-12 \%$ & $-19 \%$ & 18.9 & 127.9 \\
\hline $\begin{array}{l}\text { A combined treatment: resurfacing, crash cushion installation, } \\
\text { barrier treatments, on a dual-carriageway road (1) }{ }^{*}\end{array}$ & - & $-17 \%$ & - & 104.1 \\
\hline $\begin{array}{l}\text { Pavement treatments, road marking, raised pavement markers, } \\
\text { on a single-carriageway road (1)* } \\
\text { Infrastructure improvements at junctions }\end{array}$ & - & $-23 \%$ & - & 18.0 \\
\hline Building a roundabout (9) & $-52 \%$ & - & 10.2 & - \\
\hline Traffic lights' installation (14) & $-29 \%$ & - & 10.5 & - \\
\hline Signing arrangement at a junction (4) * & - & $-36 \%$ & - & 14.5 \\
\hline Resurfacing, barrier treatments, at a signalized junction (7) & $-20 \%$ & $-19 \%$ & 8.9 & 40.5 \\
\hline Barrier treatments, at a signalized junction (9) & $-28 \%$ & $-11 \%$ & 15.3 & 25.4 \\
\hline Pavement treatments, at a signalized junction $(2) *$ & $-50 \%$ & $-25 \%$ & 8.8 & 8.7 \\
\hline \multicolumn{5}{|l|}{ Infrastructure improvements on interchanges } \\
\hline Building roundabouts on the interchange (1) * & $-72 \%$ & - & 2.6 & - \\
\hline Barrier treatments $(2) *$ & - & $-28 \%$ & - & 15.0 \\
\hline Ramps' resurfacing (4) * & $-23 \%$ & - & 14.3 & - \\
\hline
\end{tabular}

Notes: ${ }^{1}$ Injury accidents + "general with casualties" accidents;

\# number of sites treated

* Further monitoring is required. "-" value is not available

A number of treatments estimated for Israeli conditions were combined, i.e. reflected several infrastructure improvements applied simultaneously at a site. At the same time, in the international literature, typically single treatment values are provided. Thus, certain caution is still required in using the combined treatment effects coming from the current study as those are not supported yet by the international expertise. It should be noted here that presently a common way of proceeding to produce a combined effect of several treatments is based on the assumption of independence of those treatments $[6,20]$. However, as indicated by Elvik [6], other approaches are possible, including an empirical estimate of combined effects as performed in the current study.

Being aware of the lower quality of accident data coming from the "general with casualties" accident files, some evaluation results based on this accident type, nevertheless, were kept in the final list of safety effects provided by the study. The reason for keeping them was two-fold: first, the accident reductions observed were significant and in line with the common expectations from the treatments considered; second, they may be useful for sensitivity analysis of the results, across various accident types, and for future monitoring and estimations of the effects of similar treatments, as recommended by OECD [20]. On the other hand, the results clearly conflicting with international experience (e.g. the effect of minor geometric realignment at junction) were removed from the final list of safety effects.

Some values of safety effects were based on a relatively small number of the sites treated (e.g. all infrastructure improvements at interchanges; pavement treatments at a 
signalized junction), showed a difference compared to previous estimates of similar treatments (e.g. signing arrangement at a junction) or cannot be directly supported by internationally available findings, mostly, due to a combined character of local treatments, e.g. resurfacing, crash cushion installation, barrier treatments, on a dual-carriageway road section; pavement treatments, road marking, raised markers, on a singlecarriageway road section. For such results further monitoring of safety effects is required in the future (as indicated in Table 5).

On the other hand, for a range of other infrastructure improvements considered by the study, such as changes in traffic signal program, resurfacing and replacing lenses by LEDs, at junctions, the values of accident reduction factors were not obtained, to a certain extent, due to small samples of sites of those treatments. Based on the international expertise [7], a positive safety potential of such infrastructure improvements can be expected. Thus, it is reasonable to continue with monitoring of safety effects of such treatments, under local conditions.

The study demonstrated that accident savings associated with the infrastructure improvements implemented during the black-spots' treatment project, were essential and having a tangible economic value. At the same time, the value of estimated safety benefits can be considered as conservative as it is related only to those treatments for which significant safety effects were found by the study.

The safety effects values provided by the study may serve as a supplement to the knowledge base of the Safety Management System maintained by the NTIC [9]. The accident reduction factors may be useful when infrastructure improvements are selected for treating black-spot sites on rural roads or where the economic feasibility of future investments in safer road infrastructure is discussed.

Moreover, a common trend of today can be mentioned where the authorities are encouraged to apply efficiency assessment tools, e.g. cost-benefit and cost-effectiveness analyses, for selecting measures in order to maximize the social benefits of public investments [20]. Safety effect values constitute a core element of these processes. Thus, a demand for safety effect estimates of road infrastructure improvements and other safety-related measures is expected to grow in the future.

In order to continue the updating of knowledge concerning the safety efficiency of road infrastructure treatments in the country, there is a need for a mechanism for systematic monitoring of infrastructure improvements implemented on the roads. It is recommended to maintain a database that relies on systematic reporting which would keep the information on locations, times and topics of the infrastructure improvements applied in the field, both within the road maintenance and development projects of the NTIC and other agencies involved.

Acknowledgments This research was supported by the National Transport Infrastructure Company of Israel - Netivey Israel.

\section{Appendix Accident counts observed at the sites treated, by treatment type}

\begin{tabular}{|c|c|c|c|c|c|c|}
\hline \multicolumn{7}{|l|}{ (a) On road sections } \\
\hline \multirow{2}{*}{$\begin{array}{l}\text { Type of infrastructure } \\
\text { improvement (No of } \\
\text { sites) }\end{array}$} & \multicolumn{2}{|c|}{$\begin{array}{l}\text { Injury } \\
\text { accidents }\end{array}$} & \multicolumn{2}{|c|}{$\begin{array}{l}\text { Severe } \\
\quad \text { accidents }\end{array}$} & \multicolumn{2}{|c|}{$\begin{array}{l}\text { Total } \\
\text { accidents }\end{array}$} \\
\hline & before & after & before & after & before & after \\
\hline $\begin{array}{l}\text { Upgrading a single- } \\
\text { carriageway to a dual- } \\
\text { carriageway road section } \\
\text { (2) }\end{array}$ & 202 & 79 & 28 & 10 & 422 & 269 \\
\hline $\begin{array}{l}\text { Building a median on a road } \\
\text { section crossing an urban } \\
\text { area (2) }\end{array}$ & 42 & 26 & 8 & 3 & 132 & 60 \\
\hline $\begin{array}{l}\text { Barrier installation - build- } \\
\text { ing a rigid median, on a } \\
\text { single-carriageway road } \\
\text { (4) }\end{array}$ & 91 & 36 & 25 & 5 & 137 & 128 \\
\hline $\begin{array}{l}\text { A combined treatment: } \\
\text { barriers, road marking/ } \\
\text { signing, on a single- } \\
\text { carriageway road (4) }\end{array}$ & 148 & 109 & 34 & 33 & 278 & 259 \\
\hline $\begin{array}{l}\text { A combined treatment: } \\
\text { barriers, road marking/ } \\
\text { signing, on a dual- } \\
\text { carriageway road (3) }\end{array}$ & 283 & 289 & 67 & 46 & 920 & 1,082 \\
\hline $\begin{array}{l}\text { A combined treatment: } \\
\text { resurfacing, road } \\
\text { marking, barriers' } \\
\text { treatment, on a } \\
\text { single-carriageway } \\
\text { road (6) }\end{array}$ & 343 & 234 & 64 & 50 & 692 & 691 \\
\hline $\begin{array}{l}\text { A combined treatment: } \\
\text { resurfacing, road } \\
\text { marking, barriers' } \\
\text { treatment, on a dual- } \\
\text { carriageway road (6) }\end{array}$ & 1,119 & 889 & 164 & 118 & 3,818 & 5,257 \\
\hline $\begin{array}{l}\text { A combined treatment: } \\
\text { barriers, resurfacing, } \\
\text { shoulders, on a } \\
\text { single-carriageway } \\
\text { road }(5)\end{array}$ & 575 & 416 & 84 & 71 & 1,474 & 1,607 \\
\hline $\begin{array}{l}\text { A combined treatment: } \\
\text { signs, pavement, } \\
\text { shoulders, on a single- } \\
\text { carriageway road (1) }\end{array}$ & 74 & 59 & 16 & 6 & 188 & 159 \\
\hline A combined treatment: & 189 & 207 & 37 & 27 & 1,306 & 1,474 \\
\hline
\end{tabular}

resurfacing, crash cushions' installation, barriers' treatment, on a dual-carriageway road (1) 
Pavement treatments, including road marking, raised markers, on a single-carriageway road (1)

(b) At junctions

Type of infrastructure improvement (No of sites)

Building a roundabout (9) Traffic lights' installation (14)

Minor geometric realignment at a signalized junction (26)

Signing arrangement at

junction (4)

$\begin{array}{lllllll}\text { Replacing lenses by LEDs, } & 157 & 75 & 13 & 3 & 257 & 124\end{array}$ at a signalized junction (11)

Resurfacing junction and replacing lenses by LEDs (3)

$\begin{array}{lllllll}\text { Resurfacing and barrier } & 169 & 103 & 22 & 9 & 676 & 506\end{array}$ treatments at a signalized junction (7)

Shoulder treatments and replacing lenses by LEDs (2)

Changes in traffic signal program and replacing lenses by LEDs, at a signalized junction (2)

Crosswalks' arrangement and signing treatment, at a signalized junction (1)

Barrier treatments, at a signalized junction (9)

Pavement treatments, at a signalized junction (2)

Installing pedestrian fences and replacing lenses by LEDs, at a signalized junction (1)

(c) On interchanges

Type of infrastructure improvement (No of sites)

$$
\begin{array}{lll}
\text { Injury } & \text { Severe } & \text { Total } \\
\text { accidents } & \text { accidents } & \text { accidents }
\end{array}
$$

before after before after before after

$\begin{array}{lllllll}\text { Realignment of junction on } & 11 & 16 & 1 & 2 & 133 & 74\end{array}$ the interchange (1)

$\begin{array}{lllllll}\text { Building roundabouts on } & 15 & 3 & 3 & 1 & 20 & 5\end{array}$ the interchange (1)

$\begin{array}{lllllll}\text { Barrier treatments (2) } & 34 & 32 & 5 & 0 & 274 & 115\end{array}$

$\begin{array}{lllllll}\text { Traffic signal installation at } & 8 & 2 & 2 & 0 & 22 & 8\end{array}$ a junction (1)

$\begin{array}{lllllll}\text { Ramps' resurfacing (4) } & 207 & 132 & 22 & 13 & 601 & 690\end{array}$

Open Access This article is distributed under the terms of the Creative Commons Attribution License which permits any use, distribution, and reproduction in any medium, provided the original author(s) and the source are credited.

\section{References}

1. Austroads (2010) Road Safety Engineering Risk Assessment Part 6: Crash Reduction Factors. (Austroads Technical Report AP-T151/10) Sydney, Australia: Austroads Ltd

2. Austroads (2012) Effectiveness of Road Safety Engineering Treatments (Austroads Publication AP-R422-12). Sydney, Australia: Austroads Ltd

3. CBS [Central Bureau of Statistics] (2012) Road accidents with casualties General summaries: Part A. (Publication No 1492). Jerusalem, Israel: CBS

4. EC [European Commission] (2008) Directive 2008/96/EC of the European Parliament and of the Council of 19 November 2008 on road infrastructure safety management. Off J Eur Union 319:59-67

5. Elvik R and Vaa T (2004) The Handbook of Road Safety Measures. Elsevier

6. Elvik R (2009) An exploratory analysis of models for estimating the combined effects of road safety measures. Accid Anal Prev 41(4): $876-880$

7. Elvik R, Hoya A, Vaa T, Sorensen M (2009) The Handbook of Road Safety Measures, 2nd edn. Publishing, Emerald Group

8. Gitelman V, Hakkert AS, Doveh E, Cohen A (2001) A Study of Safety Effects of Road Infrastructure Improvements under Israeli Conditions In: Proceedings of International Conference Traffic Safety on Three Continents (VTI konferens CD-ROM) Linkoping, Sweden: Swedish National Road and Transport Research Institute (VTI)

9. Gitelman V, Doveh E, Hakkert S (2008) Development of road safety management system. (Research Report 311/2008, Transportation Research Institute). Haifa, Israel: Technion - Israel Institute of Technology

10. Gitelman V, Hakkert S, Pesahov F (2009) Evaluation of safety efficiency of road infrastructure improvements implemented on rural roads. (Research Report 320/2009, Transportation Research Institute). Haifa, Israel: Technion - Israel Institute of Technology

11. Griffith MS (1999) Statistical Analysis Techniques Chapter 4 in. Statistical Evaluation in Traffic Safety Studies. Washington, D.C.: Institute of Transportation Engineers

12. Hakkert S, Wesemann P (eds) (2005) The use of efficiency assessment tools: solutions to barriers. Workpackage 3 of the European research project ROSEBUD. (SWOV Research Report R-2005-2). SWOV Institute for Road Safety Research, Leidschendam, The Netherlands

13. Harkey DL, Srinivasan R, Baek J, Council FM et al. (2008) Accident modification factors for traffic engineering and ITS improvements. (National Cooperative Highway Research Program (NCHRP) Report 617). Washington, D.C.: Transportation Research Board

14. Hasson P, Kauppila J, Assing K, Yannis G, Lassarre S (2012) Challenges and opportunities for the assessment of the effectiveness of road safety measures. Procedia - Social and Behavioral Sciences 48:3230-3238. doi:10.1016/j.sbspro.2012.06.1289

15. Hauer E (1997) Observational Before-After Studies in Road Safety. Pergamon

16. HSM [Highway Safety Manual] (2010) American Association of State Highway and Transportation Officials (AASHTO), Washington, D.C

17. Lord D and Bonneson JA (2006) Role and Application of Accident Modification Factors within Highway Design Process. Transportation Research Record: Journal of the Transportation Research Board 1961: 65-73. Transportation Research Board of the National Academies, Washington, D.C.

18. NRSA [National Road Safety Authority] (2011) Trends in road safety in Israel 2001-2010. NRSA, Jerusalem, Israel 
19. Nohal Prat (2006) Guidelines on feasibility assessment of transport projects. Ministry of Transport and Ministry of Finance, Jerusalem, Israel

20. OECD [Organisation for Economic Co-operation and Development] (2012) Sharing Road Safety: Developing an International Framework for Crash Modification Functions. OECD Publishing. http:// dx.doi.org/10.1787/9789282103760-en.

21. Ogden KW (1996) Safer Roads: A Guide to Road Safety Engineering. Avebury Technical, England

22. Persaud B, Lyon C (2007) Empirical Bayes Before-After Safety Studies: Lessons Learned From Two Decades of Experience and Future Directions. Accid Anal Prev 39:546-555
23. WHO [World Health Organization] (2013). Global status report on road safety 2013: supporting a decade of action. http://www.who.int/violence_injury_prevention/road_safety_ status/2013/en/index.html

24. Yannis G, Gitelman V, Papadimitriou E, Hakkert AS, Winkelbauer M (2008) Testing a framework for the assessment of road safety measures. Transp Rev 28(3):281-301

25. Yannis G, Weijermars W (2012) Kauppila J (2012) A review of international sources for road safety measures assessment. Procedia - Social and Behavioral Sciences 48:2876-2886. doi:10.1016/j. sbspro.2012.06.1256 